Int. J. Electrochem. Sci., 14 (2019) $6209-6222$

\title{
Corrosion of N80 Steel in a Concentrated Tetrapotassium Pyrophosphate Solution and Corrosion Control by Vanadates
}

\author{
Jingmao Zhao ${ }^{1,2, *}$, Qiuxiang Yang ${ }^{1}$, Chen Zhang ${ }^{1,3}$, Yuwu Wang ${ }^{1}$ \\ ${ }^{1}$ College of Material Science and Engineering, Beijing University of Chemical Technology, Beijing \\ 100029, China \\ ${ }^{2}$ Beijing Key Laboratory of Electrochemical Process and Technology for Materials, Beijing 100029, \\ China \\ ${ }^{3}$ South China Branch, Sinopec Sales Co., Ltd., Guangzhou 510620, China \\ Correspondence \\ *E-mail: jingmaozhao@126.com
}

doi: $10.20964 / 2019.07 .35$

Received: 9 September 2018 / Accepted: 25 October 2018 / Published: 10 June 2019

The main purpose of this work is to study the corrosion of N80 steel in a concentrated tetrapotassium pyrophosphate (TKPP) solution at different temperatures and to evaluate the corrosion inhibition performance of relevant chemicals for N80 steel in this solution. This study employed the methods of weight loss, potentiodynamic polarization, electrochemical impedance spectroscopy (EIS), and X-ray photoelectron spectroscopy (XPS). The temperature had a significant influence on the corrosion rate of N80 in solution. Specifically, the corrosion rate was moderate at low temperatures, but increased dramatically when the temperature exceeded $90{ }^{\circ} \mathrm{C}$. At a temperature of $120^{\circ} \mathrm{C}$, the rate was as high as 731 mpy. Among the chemicals investigated, dichromates and vanadates showed excellent inhibition performance. The inhibition induced by vanadates was mainly due to the promotion of carbon steel passivation. In the presence of $0.5 \mathrm{wt}$. $\%$ vanadate, the corrosion rate of $\mathrm{N} 80$ steel can be controlled to less than 3 mpy at a temperature of $120^{\circ} \mathrm{C}$.

Keywords: TKPP, corrosion inhibitor, N80 steel, vanadate

\section{FULL TEXT}

(C) 2019 The Authors. Published by ESG (www.electrochemsci.org). This article is an open access article distributed under the terms and conditions of the Creative Commons Attribution license (http://creativecommons.org/licenses/by/4.0/). 